Check for updates

Cite this: Chem. Sci., 2018, 9, 8836

๑ All publication charges for this article have been paid for by the Royal Society of Chemistry

Received 21st August 2018

Accepted 22nd September 2018

DOI: $10.1039 / \mathrm{c} 8 \mathrm{sc} 03730 \mathrm{~b}$

rsc.li/chemical-science

\section{Silver-mediated oxidative functionalization of alkylsilanes $\dagger$}

\author{
Feng Wang, \$ Peng Xu, \$Fei Cong and Pingping Tang (D) * \\ A general approach to the functionalization of aliphatic C-Si bonds in the presence of silver salts and \\ oxidants has been reported. This strategy encompasses a range of valuable $\mathrm{C}-\mathrm{Si}$ transformations, \\ including the direct conversions of a $\mathrm{C}-\mathrm{Si}$ bond to $\mathrm{C}-\mathrm{OCF}_{3}, \mathrm{C}-\mathrm{OBz}, \mathrm{C}-\mathrm{OCOCF}_{3}, \mathrm{C}-\mathrm{SCF}_{3}, \mathrm{C}-\mathrm{SCN}$, and \\ $\mathrm{C}-\mathrm{N}_{3}$ bonds. Among them, trifluoromethoxylation of alkylsilanes is reported for the first time. In addition, \\ mechanistic studies indicate that this reaction may proceed through a radical mechanism.
}

Organosilicon compounds have a multitude of applications in basic science, medicine, and industry due to their stability and non-toxicity, and natural abundance of silicon. ${ }^{1}$ For example, organosilicon compounds have received much attention in the cross-coupling reaction. ${ }^{2}$ However, the strategic functionalization of aliphatic carbon-silicon bonds is limited, ${ }^{3}$ for example, the trifluoromethoxy $\left(\mathrm{OCF}_{3}\right)$ group and trifluoromethylthio $\left(\mathrm{SCF}_{3}\right)$ group are becoming increasingly important in medicinal, agrochemical and materials science due to their strong electronwithdrawing effect and high lipophilicity. ${ }^{4}$ Thus, the development of efficient methods for the synthesis of $\mathrm{OCF}_{3}$ and $\mathrm{SCF}_{3}$ compounds is of great importance., ${ }^{5,6}$ However, the trifluoromethoxylation and trifluoromethylthiolation of organosilanes are extremely underdeveloped. ${ }^{7}$ To the best of our knowledge, no trifluoromethoxylation of alkylsilanes has been reported to date. Herein, we sought a strategy that would facilitate the direct conversion of aliphatic C-Si bonds into a variety of functional groups, including the trifluoromethoxylation and trifluoromethylthiolation of alkylsilanes (Scheme 1).

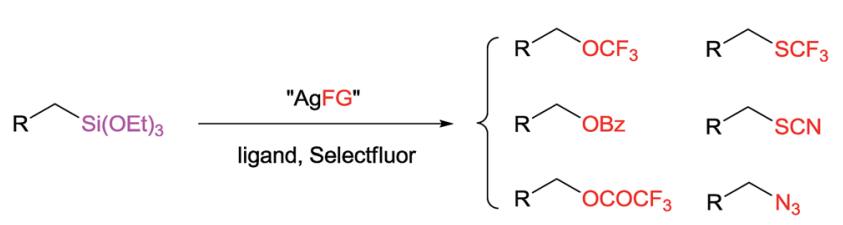

$\mathrm{FG}=\mathrm{OCF}_{3}, \mathrm{OBz}, \mathrm{OCOCF}_{3}, \mathrm{SCF}_{3}, \mathrm{SCN}, \mathrm{N}_{3}$

Scheme 1 Silver-mediated oxidative functionalization of alkylsilanes.

State Key Laboratory and Institute of Elemento-Organic Chemistry, College of Chemistry, Collaborative Innovation Center of Chemical Science and Engineering (Tianjin), Nankai University, Tianjin 300071, China.E-mail: ptang@nankai.edu.cn $\dagger$ Electronic Supplementary Information (ESI) available: Data for new compounds and experimental procedures. See DOI: 10.1039/c000000x/.

$\ddagger$ These authors contributed equally to this work.
Methods for aliphatic C-Si oxidation, ${ }^{8}$ halogenation, ${ }^{9}$ and azidation ${ }^{10}$ have been reported, but new reaction systems are typically required to promote each transformation. In addition, methods for trifluoromethoxylation of organosilanes are rare, and only two examples were reported. In 2008, using trifluoromethyl triflate as the trifluoromethoxylation reagent, the Kolomeitsev group reported the trifluoromethoxylation of arynes from $o$-trimethylsilylphenyl triflate. ${ }^{7 a}$ In 2018 , trifluoromethyl benzoate (TFBz) was reported as a new trifluoromethoxylation reagent by the Hu group and was used to prepare trifluoromethyl ether from trifluoromethoxylation-halogenation of arynes, which was in situ generated from $o$-trimethylsilylphenyl triflate. ${ }^{7 g}$ Despite the advances in these methods, trifluoromethoxylation of alkylsilanes has not been reported to date, so the development of a general approach for functionalization including trifluoromethoxylation of alkylsilanes is highly desirable.

Inspired by our previous work of a hypervalent iodinemediated fluorination of alkylsilanes using fluoride ions as the fluorinating agent, ${ }^{9 e}$ we became interested in the possibility of functionalization of alkylsilanes using other nucleophiles such as ${ }^{-} \mathrm{OCF}_{3}$. Recently, trifluoromethyl arylsulfonate (TFMS) as a new trifluoromethoxylation reagent was disclosed by our group, which was used to in situ generate $\mathrm{AgOCF}_{3}$ in the presence of silver salts and fluoride ions. ${ }^{11}$ Thus, we envisioned whether the oxidative trifluoromethoxylation of alkylsilanes could be achieved with ${ }^{-} \mathrm{OCF}_{3}$ which was in situ generated in the presence of fluoride ions and TFMS. Initial investigations focused on the reaction of alkylsilane $\mathbf{1}$ with various fluorine sources in the presence of trifluoromethyl 4-methylbenzenesulfonate (TFMS, 2) (Table 1, see more details in the ESI†). No desired product 3a was observed when $\mathrm{Et}_{3} \mathrm{~N} \cdot 3 \mathrm{HF}$, CsF, TBAF or $\mathrm{FeF}_{3}$ was used as the fluoride ion source (Table 1, entries 1-4). We were delighted to find that $61 \%$ yield of the desired product 3a was observed in the presence of AgF (Table 1, entry 5). Different ligands were evaluated, and 3,4,7,8tetramethyl-1,10-phenanthroline gave the highest yield (Table 
Table 1 Optimized reaction conditions ${ }^{a}$

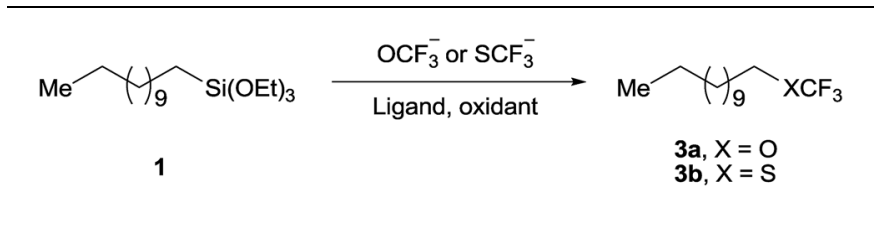

\begin{tabular}{|c|c|c|c|c|}
\hline Entry & ${ }^{-} \mathrm{OCF}_{3}$ or ${ }^{-} \mathrm{SCF}_{3}$ & Ligand & Oxidant & Yield (\% \\
\hline 1 & $\mathrm{Et}_{3} \mathrm{~N} \cdot 3 \mathrm{HF}$, TFMS (2) & 3,4,7,8-Me ${ }_{4}$-Phen & Selectfluor & $3 \mathbf{a}, 0$ \\
\hline 2 & CsF, TFMS (2) & 3,4,7,8-Me ${ }_{4}$-Phen & Selectfluor & $3 a, 0$ \\
\hline 3 & TBAF, TFMS (2) & $3,4,7,8-\mathrm{Me}_{4}$-Phen & Selectfluor & $3 a, 0$ \\
\hline 4 & $\mathrm{FeF}_{3}, \mathrm{TFMS}(2)$ & 3,4,7,8-Me $\mathrm{Me}_{4}$-Phen & Selectfluor & $3 a, 0$ \\
\hline 5 & AgF, TFMS (2) & 3,4,7,8- $\mathrm{Me}_{4}$-Phen & Selectfluor & $3 a, 61$ \\
\hline 6 & AgF, TFMS (2) & Phen & Selectfluor & $3 a, 45$ \\
\hline 7 & AgF, TFMS (2) & Neocuproine & Selectfluor & $3 \mathbf{a}, 8$ \\
\hline 8 & AgF, TFMS (2) & 4,7-Ph - -Phen & Selectfluor & $3 a, 52$ \\
\hline 9 & AgF, TFMS (2) & 5,6-Dione-Phen & Selectfluor & $3 a, 2$ \\
\hline 10 & AgF, TFMS (2) & dtbpy & Selectfluor & $3 a, 56$ \\
\hline 11 & AgF, TFMS (2) & $3,4,7,8-\mathrm{Me}_{4}$-Phen & NFSI & $3 a, 0$ \\
\hline 12 & AgF, TFMS (2) & $3,4,7,8-\mathrm{Me}_{4}$-Phen & PhIO & $3 a, 0$ \\
\hline 13 & AgF, TFMS (2) & 3,4,7,8- $\mathrm{Me}_{4}$-Phen & $\mathrm{PhI}(\mathrm{OAc})_{2}$ & $3 a, 0$ \\
\hline 14 & AgF, TFMS (2) & 3,4,7,8- $\mathrm{Me}_{4}$-Phen & $\mathrm{K}_{2} \mathrm{~S}_{2} \mathrm{O}_{8}$ & $3 a, 0$ \\
\hline $15^{b}$ & $\mathrm{AgSCF}_{3}$ & dtbpy & Selectfluor & $3 \mathbf{b}, 80$ \\
\hline
\end{tabular}

${ }^{a}$ General conditions: 1 (1.0 equiv.), silver salt (4.0 equiv.), TFMS (2) (5.0 equiv.), ligand (0.3 equiv.), oxidant (3.0 equiv.), MeCN/DCM (v/v $7: 2$ ), $25{ }^{\circ} \mathrm{C}, \mathrm{N}_{2} .{ }^{b} \mathrm{AgSCF}_{3}$ (4.0 equiv.), CsF (4.0 equiv.), dtbpy (0.4 equiv.), Selectfluor (3.0 equiv.), MeCN/dioxane (v/v 1:1), $50{ }^{\circ} \mathrm{C}, \mathrm{N}_{2} .{ }^{c}$ Yields were determined by ${ }^{19} \mathrm{~F}$ NMR with benzotrifluoride as a standard.

1, entries 5-10). Switching to other oxidants such as $\mathrm{N}$-fluorobenzenesulfonimide (NFSI), PhIO, PhI $(\mathrm{OAc})_{2}$, and $\mathrm{K}_{2} \mathrm{~S}_{2} \mathrm{O}_{8}$ could not generate $3 a$ (Table 1, entries 11-14). No desired products were detected in control experiments with AgF or the oxidant omitted. After extensive screening of various solvents, different substitutions on TFMS, and temperatures (see more details in the ESI $\dagger$ ), the ideal conditions of 4.0 equiv. of AgF, 0.3 equiv. of 3,4,7,8-tetramethyl-1,10-phenanthroline, 3.0 equiv. of Selectfluor, and 5.0 equiv. of TFMS (2) in $7: 2$ (v:v) MeCN/DCM under a $\mathrm{N}_{2}$ atmosphere at $25{ }^{\circ} \mathrm{C}$ were found to produce the highest yields. Encouraged by these results, we successfully extended the present system to a trifluoromethylthiolation of alkylsilanes by changing the ligand and silver salt. After optimization of the reaction conditions, the desired trifluoromethylthiolated product (3b) was obtained in $80 \%$ yield using 4.0 equiv. of $\mathrm{AgSCF}_{3}, 0.4$ equiv. of $4,4^{\prime}$-di-tert-butyl-2,2'bipyridine, 3.0 equiv. of Selectfluor, and 4.0 equiv. of CsF in $1: 1$ (v: v) MeCN/dioxane under a $\mathrm{N}_{2}$ atmosphere at $50{ }^{\circ} \mathrm{C}$ (Table 1, entry 15 , see more details in the $\mathrm{ESI}_{\dagger}^{\dagger}$ ).

Having established optimized reaction conditions, we then explored the scope of trifluoromethoxylation and trifluoromethylthiolation with structurally diverse alkylsilanes. As displayed in Table 2, a wide range of primary alkylsilanes bearing electron-donating and electron-withdrawing substituents on aryl rings were successfully converted into the desired trifluoromethoxylated and trifluoromethylthiolated products with good isolated yields (4 to 16). Notably, heteroaromatic substrates, such as pyridine, indole, and thiophene, were also successfully employed to provide the corresponding trifluoromethoxylated and trifluoromethylthiolated products (17 to 21). A good range of functional groups including ester, ether, ketone, nitrile, nitro, amide, chloride, bromide, and even iodide were well tolerated under the mild reaction conditions. Moreover, the trifluoromethylthiolation of an alkylsilane with tertiary alcohol also proceeded smoothly (36). These results encouraged the application of this method to more complex small molecules, which gave the corresponding trifluoromethoxylated and trifluoromethylthiolated products in moderate yields (39, 40 and 41), for example, the alkylsilane derived from celecoxib, which is a nonsteroidal anti-inflammatory drug, was converted to the trifluoromethoxylated product (40a) in $31 \%$ yield or trifluoromethylthiolated product (40b) in $57 \%$ yield. In addition, we prepared compounds $\mathbf{5 a}$ and $\mathbf{5 b}$ at the gram scale under the standard reaction conditions in $44 \%$ and $69 \%$ isolated yields, respectively, which demonstrates the scalability of this method. However, trifluoromethoxylation and trifluoromethylthiolation of secondary alkylsilanes were observed with low yields (37 and 38), and alkenes were the major byproducts.

Encouraged by our success with trifluoromethoxylation and trifluoromethylthiolation of alkylsilanes, we investigated the use of other silver salts to develop the functionalization of alkylsilanes (Table 3). When AgOBz, $\mathrm{AgOCOCF}_{3}$, or AgSCN was used, the corresponding products $(\mathbf{4 2}, \mathbf{4 3}$, and 44$)$ were obtained in moderate yields. Installation of an azide group has proven to be useful in chemical biology, medicinal chemistry, and materials science. ${ }^{12}$ The use of $\mathrm{AgF}$ and $\mathrm{TsN}_{3}$ enabled azidation of alkylsilane 1 to prepare the desired product 45 in $63 \%$ isolated yield. We note that in each system, both the silver salt and oxidant were necessary for productive reactivity. Although these reactions are not fully optimized, they provide a general strategy for the functionalization of alkylsilanes.

To gain some insight into the reaction mechanism, we performed some preliminary studies (Scheme 2a). A less than 10\% trifluoromethoxylated or trifluoromethylthiolated product was formed when a radical inhibitor 2,6-di-tert-butyl-4methylphenol (BHT) (8 equiv.) was added. In addition, when 4 equiv. of 2,2,6,6-tetramethyl-1-piperidinyloxy (TEMPO) was added, the TEMPO adduct 46 or 47 was obtained in $25 \%$ and $38 \%$ isolated yield, respectively. Furthermore, the reaction of alkanesilanes under the standard reaction conditions (conditions B) gave the trifluoromethylthiolated product 48 (37\%) along with the 5-exo-cyclization trifluoromethylthiolated product $48^{\prime}$ in $12 \%$ yield. Together, these observations strongly suggested that a radical-chain mechanism or single-electron transfer (SET) was involved in the reactions. In addition, a $28 \%$ trifluoromethoxylated product was obtained when $\mathrm{AgF}_{2}$ was used in the absence of AgF and Selectfluor, which indicated that Ag(II) species could be involved in the reaction (see more details in the ESI $\dagger$ ). Finally, a silver mirror was observed in the reaction, which suggested that $\operatorname{Ag}(0)$ was generated.

On the basis of these mechanistic investigations, we proposed the mechanism depicted in scheme $2 \mathrm{~b}$. In the presence of ligand and Selectfluor, AgFG $\left(\mathrm{FG}=\mathrm{OCF}_{3}, \mathrm{OBz}\right.$, $\mathrm{OCOCF}_{3}, \mathrm{SCF}_{3}, \mathrm{SCN}, \mathrm{N}_{3}$ ) is oxidized to produce $\mathrm{Ag}$ (II) intermediate $\mathbf{I}^{\mathbf{1 1 d}}$ then $\mathrm{R}$ group transmetalation from silicon to $\mathrm{Ag}$ (II) intermediate I can afford alkylsilver species II. The 
Table 2 Substrate scope for silver-mediated oxidative trifluoromethoxylation and trifluoromethylthiolation of alkylsilanes ${ }^{a}$

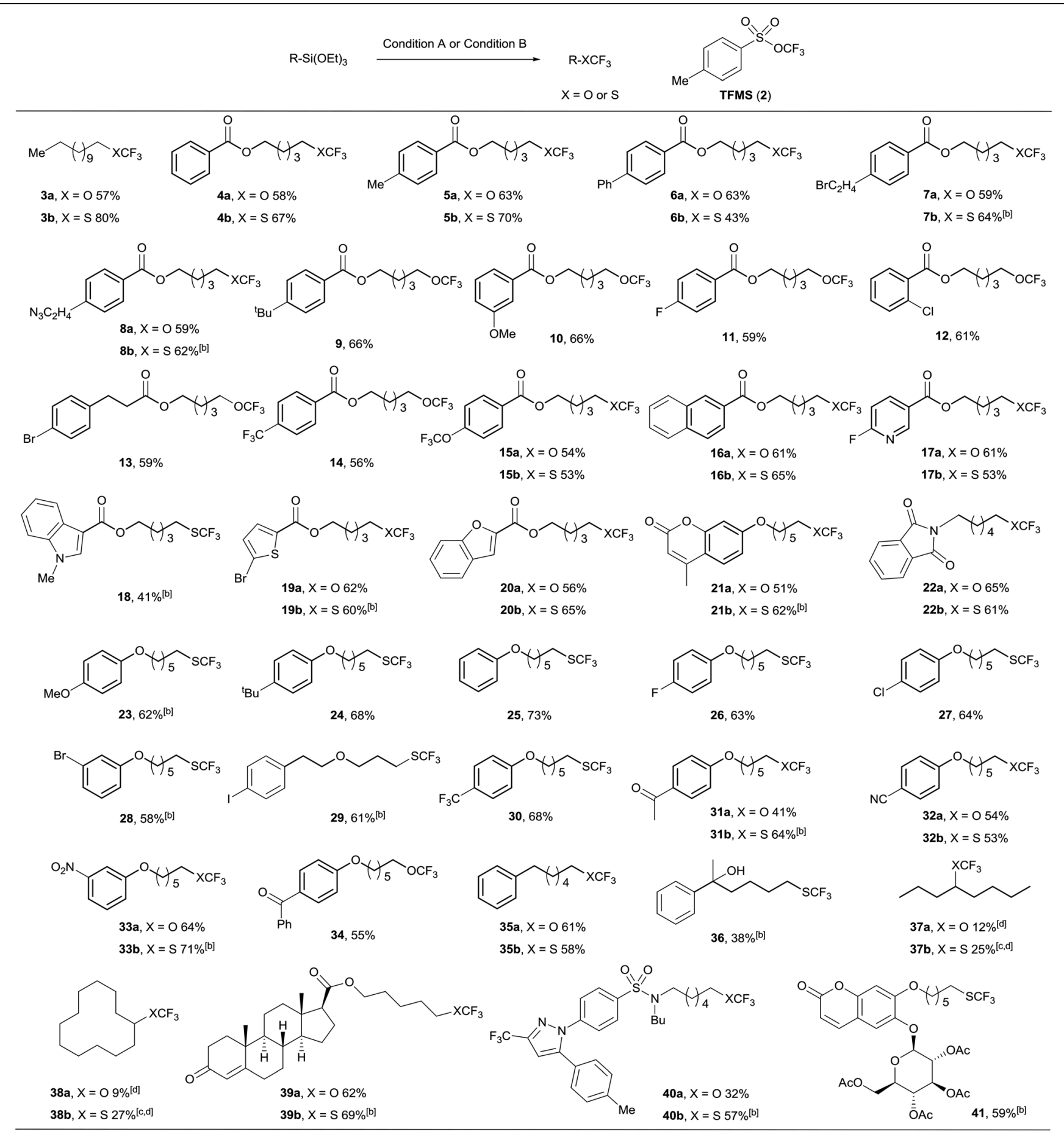

${ }^{a}$ Conditions A: alkylsilanes (1.0 equiv.), AgF (4.0 equiv.), 3,4,7,8-tetramethyl-1,10-phenanthroline (0.3 equiv.), Selectfluor (3.0 equiv.), TFMS (2) (5.0 equiv.), MeCN/DCM (v/v $7: 2$ ), $\mathrm{N}_{2}$ atmosphere, $25^{\circ} \mathrm{C}$. Conditions B: alkylsilanes (1.0 equiv.), AgSCF 3 (4.0 equiv.), 4,4'-di-tert-butyl-2,2'-bipyridine (0.4 equiv.), Selectfluor (3.0 equiv.), $\mathrm{CsF}$ (4.0 equiv.), MeCN/dioxane (v/v $1: 1), \mathrm{N}_{2}$ atmosphere, $50^{\circ} \mathrm{C}$. Yields of isolated products are given. ${ }^{b} 25^{\circ} \mathrm{C}$ was used. ${ }^{c}$ MeCN/DCM (v/v $1: 1$ ) was used. ${ }^{d}$ Yield was determined by ${ }^{19} \mathrm{~F}$ NMR with benzotrifluoride as a standard.

subsequent single-electron transfer between $\mathrm{Ag}$ (II) and the $\mathrm{R}$ group in intermediate II leads to the generation of the $\mathrm{R}$ radical and $A g(I)$ species III. Finally, the FG group transfer from the intermediate III to the R radical generates RFG and
$\operatorname{Ag}(0)$. At present, we cannot rule out the possibility of an alternative mechanism in which the $\mathrm{R}$ radical intermediate is further oxidized to generate an $\mathrm{R}$ carbocation intermediate, which is trapped by the FG anion to form the desired product. 
Table 3 Substrate scope for silver-mediated oxidative functionalization of alkylsilanes

\begin{tabular}{|c|c|c|c|}
\hline & $\begin{array}{ll}\mathrm{H}_{9} & \mathrm{Si}(\mathrm{OEt})_{3} \\
1 & \end{array}$ & $\begin{array}{c}\text { "AgFG" } \\
\text { Ligand, Selectfluor }\end{array}$ & Ho \\
\hline Entry & AgFG & Ligand & Yield \\
\hline 1 & $\mathrm{AgOBz}$ & $3,4,7,8-\mathrm{Me}_{4}$-Phen & $\begin{array}{c}\mathrm{Me}_{\mathbf{4 2}}, 61 \% \\
\mathrm{M}\end{array}$ \\
\hline 2 & $\mathrm{AgOCOCF}_{3}$ & 4,7- $\mathrm{MeO}_{2}$-Phen & $\mathrm{Me}$ \\
\hline 3 & AgSCN & $4,4^{\prime}-\mathrm{MeO}_{2}$-bby & $\begin{array}{l}\mathrm{Me} \\
44,43 \%\end{array}$ \\
\hline 4 & $\mathrm{AgF}+\mathrm{TsN}_{3}$ & 4,7- $\mathrm{MeO}_{2}$-Phen & $45,63 \%$ \\
\hline
\end{tabular}

${ }^{a} 1$ (1.0 equiv.), $\mathrm{AgOBz}$ (4.0 equiv.), $\mathrm{CsF}$ (4.0 equiv.), ligand ( 0.4 equiv.), Selectfluor (3.0 equiv.), MeCN/DCE (v/v 1:1), $50{ }^{\circ} \mathrm{C}, \mathrm{N}_{2} .{ }^{b} 1$ (1.0 equiv.), $\mathrm{AgOCOCF}_{3}$ (4.0 equiv.), $\mathrm{CsF}$ (4.0 equiv.), ligand ( 0.4 equiv.), Selectfluor (3.0 equiv.), DMC, $50{ }^{\circ} \mathrm{C}, \mathrm{N}_{2} .{ }^{c} 1$ (1.0 equiv.), AgSCN (4.0 equiv.), CsF (4.0 equiv.), ligand (0.4 equiv.), Selectfluor (3.0 equiv.), MeCN/DCE (v/v $1: 1), 50{ }^{\circ} \mathrm{C}, \mathrm{N}_{2} .{ }^{d} 1$ (1.0 equiv.), AgF (4.0 equiv.), $\mathrm{TsN}_{3}$ (4.0 equiv.), ligand ( 0.4 equiv.), Selectfluor (II) (3.0 equiv.), MeCN/ DCE/EtOH (v/v/v $5: 5: 1), 25{ }^{\circ} \mathrm{C}, \mathrm{N}_{2}$.

a) Mechanistic studies
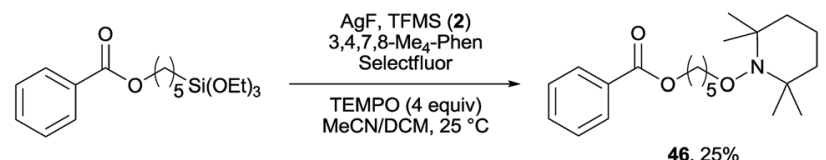

$46,25 \%$
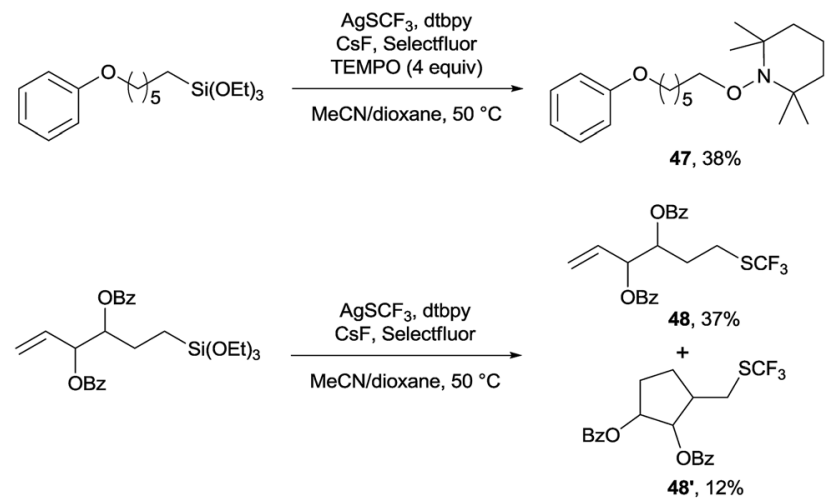

b) Proposed mechanism

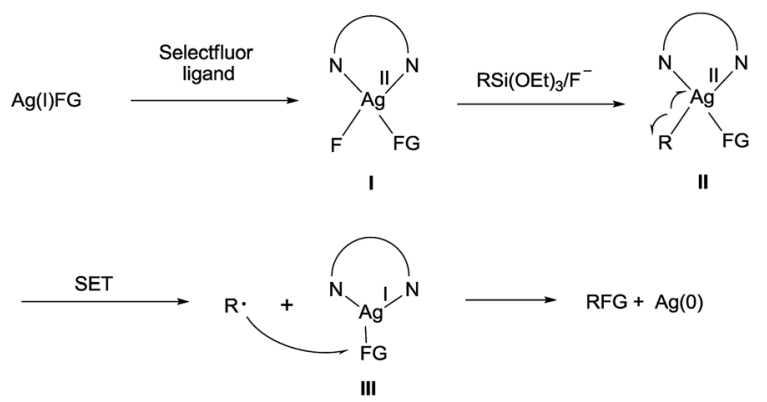

Scheme 2 (a)Mechanistic studies and (b) proposed mechanism.

\section{Conclusions}

In conclusion, we have developed a silver-mediated oxidative functionalization of alkylsilanes. This strategy enables accessing a range of functionalized products directly, thus obviating the need to develop a new methodology for each specific $\mathrm{C}-\mathrm{Si}$ transformation. Furthermore, the first example of silvermediated trifluoromethoxylation of alkylsilanes was developed using trifluoromethyl arylsulfonate (TFMS) as the trifluoromethoxylation reagent. Additionally, preliminary mechanistic studies suggested that this reaction may proceed through a radical mechanism.

\section{Conflicts of interest}

There are no conflicts to declare.

\section{Acknowledgements}

We gratefully acknowledge the State Key Laboratory of Elemento-Organic Chemistry for generous start-up financial support. This work was supported by the National Key Research and Development Program of China (2016YFA0602900) and the National Natural Science Foundation of China (21522205 and 21672110) and the Fundamental Research Funds for the Central Universities.

\section{Notes and references}

1 (a) A. Bassindale and P. P. Gaspar, Frontiers of Organosilicon Chemistry, Royal Society of Chemistry, 1991; (b) G. L. Larson, Advances in Silicon Chemistry, JAI Press, 1996; (c) N. Auner and J. Weis, Organosilicon Chemistry $V$, Wiley-VCH Verlag $\mathrm{GmbH}, 2003$.

2 (a) T. Hiyama, Metal-catalyzed Cross-Coupling Reactions, Wiley-VCH, Weinheim, 1998, ch. 4; (b) M. A. Brook, Silicon in Organic, Organometallic, and Polymer Chemistry, Wiley, New York, 2000; (c) S. E. Denmark and J. H. Liu, Angew. Chem., Int. Ed., 2010, 49, 2978; (d) Y. Nakao and T. Hiyama, Chem. Soc. Rev., 2011, 40, 4893; (e) H. F. Sore, W. R. J. D. Galloway and D. R. Spring, Chem. Soc. Rev., 2012, 41, 1845; (f) H. Luo, Z. Zhang, H. Liu and H. Liu, Chin. J. Org. Chem., 2015, 35, 802; $(g)$ S. E. Denmark and A. Ambrosi, Org. Process Res. Dev., 2015, 19, 982; $(h)$ H. Luo, H. Liu, X. Chen, K. Wang, X. Luo and K. Wang, Chem. Commun., 2017, 53, 956.

3 (a) L. Li, Y. Zhang, L. Gao and Z. Song, Tetrahedron Lett., 2015, 56, 1466; (b) T. Komiyama, Y. Minami and T. Hiyama, ACS Catal., 2017, 7, 631.

4 (a) A. Leo, C. Hansch and D. Elkins, Chem. Rev., 1971, 71, 525; (b) F. Leroux, P. Jeschke and M. Schlosser, Chem. Rev., 2005, 105, 827; (c) M. Shimizu and T. Hiyama, Angew. Chem., Int. Ed., 2005, 44, 214; (d) B. Menteau, S. Pazenok, J. P. Vors and F. R. Leroux, J. Fluorine Chem., 2010, 131, 140; (e) G. Landelle, A. Panossian and F. R. Leroux, Curr. Top. Med. Chem., 2014, 14, 941. 
5 For recent reviews on trifluoromethoxylation reactions, see (a) A. Tlili, F. Toulgoat and T. Billard, Angew. Chem., Int. Ed., 2016, 55, 11726; (b) T. Besset, P. Jubault, X. Pannecoucke and T. Poisson, Org. Chem. Front., 2016, 3, 1004. For selected examples of the synthesis of trifluoromethoxylated compounds, see (c) K. Stanek, R. Koller and A. Togni, J. Org. Chem., 2008, 73, 7678; (d) R. Koller, K. Stanek, D. Stolz, R. Aardoom, K. Niedermann and A. Togni, Angew. Chem., Int. Ed., 2009, 48, 4332; (e) O. Marrec, T. Billard, J. Vors, S. Pazenok and B. R. Langlois, Adv. Synth. Catal., 2010, 352, 2831; (f) O. Marrec, T. Billard, J. Vors, S. Pazenok and B. R. Langlois, J. Fluorine Chem., 2010, 131, 200; $(g)$ C. Huang, T. Liang, S. Harada, E. Lee and T. Ritter, J. Am. Chem. Soc., 2011, 133, 13308; (h) C. Zhang and D. A. Vicic, Organometallics, 2012, 31, 7812; (i) K. N. Hojczyk, P. Feng, C. Zhan and M. Y. Ngai, Angew. Chem., Int. Ed., 2014, 53, 14559; (j) J. Liu, C. Chen, L. Chu, Z. Chen, X. Xu and F. Qing, Angew. Chem., Int. Ed., 2015, 54, 11839; (k) J. Liu, X. Xu and F. Qing, Org. Lett., 2015, 17, 5048; (l) C. Chen, P. Chen and G. Liu, J. Am. Chem. Soc., 2015, 137, 15648; (m) S. Chen, Y. Huang, X. Fang, H. Li, Z. Zhang, T. S. Andy Hor and Z. Weng, Dalton Trans., 2015, 44, 19682; (n) A. Liang, S. Han, Z. Liu, L. Wang, J. Li, D. Zou, Y. Wu and Y. Wu, Chem.-Eur. J., 2016, 22, 5102; (o) P. Feng, K. N. Lee, J. W. Lee, C. Zhan and M. Y. Ngai, Chem. Sci., 2016, 7, 424; (p) G. Zha, J. Han, X. Hu, H. Qin, W. Fang and C. Zhang, Chem. Commun., 2016, 52, 7458; (q) M. Zhou, C. Ni, Z. He and J. Hu, Org. Lett., 2016, 18, 3754; (r) C. Chatalova-Sazepin, M. Binayeva, M. Epifanov, W. Zhang, P. Foth, C. Amador, M. Jagdeo, B. R. Boswell and G. M. Sammis, Org. Lett., 2016, 18, 4570; (s) Q. Zhang, A. T. Brusoe, V. Mascitti, K. D. Hesp, D. C. Blakemore, J. T. Kohrt and J. F. Hartwig, Angew. Chem., Int. Ed., 2016, 55, 9758; $(t)$ J. N. Brantley, A. V. Samant and F. D. Toste, ACS Cent. Sci., 2016, 2, 341; (u) S. Krishanmoorthy, S. D. Schnell, H. Dang, F. Fu and G. K. S. Prakash, J. Fluorine Chem., 2017, 203, 130; (v) W. Huang, X. Wan and Q. Shen, Angew. Chem., Int. Ed., 2017, 56, 11986; (w) E. Schmitt, S. Bouvet, B. Pégot, A. Panossian, J. Vors, S. Pazenok, E. Magnier and F. R. Leroux, Org. Lett., 2017, 19, 4960; $(x)$ J. W. Lee, D. N. Spiegowski and M. Y. Ngai, Chem. Sci., 2017, 8, 6066; (y) C. Chen, Y. Luo, L. Fu, P. Chen, Y. Lan and G. Liu, J. Am. Chem. Soc., 2018, 140, 1207; (z) M. Zhou, C. Ni, Y. Zeng and J. Hu, J. Am. Chem. Soc., 2018, 140, 6801; ( $a a)$ W. Zheng, C. A. Morales-Rivera, J. W. Lee, P. Liu and M. Ngai, Angew. Chem., Int. Ed., 2018, 57, 9645; $(a b)$ B. J. Jelier, P. F. Tripet, E. Pietrasiak, I. Franzoni, G. Jeschke and A. Togni, Angew. Chem., Int. Ed., 2018, DOI: 10.1002/anie.201806296.

6 For recent reviews on trifluoromethylthiolation reactions, see (a) X. Shao, C. Xu, L. Lu and Q. Shen, Acc. Chem. Res., 2015, 48, 1227; (b) X. Xu, K. Matsuzaki and N. Shibata, Chem. Rev., 2015, 115, 731; (c) H. Chachignon and D. Cahard, Chin. J. Chem., 2016, 34, 445. For selected examples of the synthesis of trifluoromethylthiolated compounds, see: (d) A. Ferry, T. Billard, B. R. Langlois and E. Bacqué, Angew. Chem., Int. Ed., 2009, 48, 8551; (e) G. Teverovskiy, D. S. Surry and S. L. Buchwald, Angew. Chem., Int. Ed., 2011, 50, 7312; (f) C. Zhang and D. A. Vicic, J. Am. Chem. Soc., 2012, 134, 183; $(g)$ L. D. Tran, I. Popov and O. Daugulis, J. Am. Chem. Soc., 2012, 134, 18237; (h) X. Shao, X. Wang, T. Yang, L. Lu and Q. Shen, Angew. Chem., Int. Ed., 2013, 52, 3457; (i) T. Bootwicha, X. Liu, R. Pluta, I. Atodiresei and M. Rueping, Angew. Chem., Int. Ed., 2013, 52, 12856; (j) Y. Yang, A. Azuma, E. Tokunaga, M. Yamasaki, M. Shiro and N. Shibata, J. Am. Chem. Soc., 2013, 135, 8782; (k) E. V. Vinogradova, P. Müller and S. L. Buchwald, Angew. Chem., Int. Ed., 2014, 53, 3125; (l) G. Danoun, B. Bayarmagnai, M. F. Gruenberg and L. J. Goossen, Chem. Sci., 2014, 5, 1312; $(m)$ F. Yin and X. Wang, Org. Lett., 2014, 16, 1128; (n) J. Liu, X. Xu, Z. Chen and F. Qing, Angew. Chem., Int. Ed., 2015, 54, 897; (o) G. Yin, I. Kalvet, U. Englert and F. Schoenebeck, J. Am. Chem. Soc., 2015, 137, 4164; (p) S. Guo, X. Zhang and P. Tang, Angew. Chem., Int. Ed., 2015, 54, 4065; (q) H. Wu, Z. Xiao, J. Wu, Y. Guo, J. Xiao, C. Liu and Q. Chen, Angew. Chem., Int. Ed., 2015, 54, 4070; (r) X. Liu, R. An, X. Zhang, J. Luo and X. Zhao, Angew. Chem., Int. Ed., 2016, 54, 5846; (s) S. Mukherjee, B. Maji, A. Tlahuext-Aca and F. Glorius, $J$. Am. Chem. Soc., 2016, 138, 16200; $(t)$ L. J. C. B. Milandou, H. Carreyre, S. Alazet, G. Greco, A. Martin-Mingot, C. N. Loumpangou, J. Ouamba, F. Bouazza, T. Billard and S. Thibaudeau, Angew. Chem., Int. Ed., 2017, 56, 169; (u) Z. Zhang, Z. Sheng, W. Yu, G. Wu, R. Zhang, W. Chu, Y. Zhang and J. Wang, Nat. Chem., 2017, 9, 970.

7 (a) A. A. Kolomeitsev, M. Vorobyev and H. Gillandt, Tetrahedron Lett., 2008, 49, 449; (b) J. Liu, L. Chu and F. Qing, Org. Lett., 2013, 15, 894; (c) J. Sheng and J. Wu, Org. Biomol. Chem., 2014, 12, 7629; (d) S. Alazet, L. Zimmer and T. Billard, Chem.-Eur. J., 2014, 20, 8589; (e) S. Arimori, M. Takada and N. Shibata, Org. Lett., 2015, 17, 1063; $(f)$ Y. Zeng and J. Hu, Org. Lett., 2016, 18, 856; $(g)$ M. Zhou, C. Ni, Y. Zeng and J. Hu, J. Am. Chem. Soc., 2018, 140, 6801. 8 (a) A. G. Brook, J. Am. Chem. Soc., 1958, 80, 1886; (b) A. G. Brook, Acc. Chem. Res., 1974, 7, 77; (c) A. Riahi, J. Cossy, J. Muzart and J. P. Pete, Tetrahedron Lett., 1985, 26, 839; (d) A. S. Guram, Synlett, 1993, 4, 259; (e) C. Kaimakliotis and A. J. Fry, J. Org. Chem., 2003, 68, 9893; (f) A. B. Smith III and C. M. Adams, Acc. Chem. Res., 2004, 37, 365; (g) Y. Deng, Q. Liu and A. B. Smith III, J. Am. Chem. Soc., 2017, 139, 9487.

9 (a) K. Tamao, J. Yoshida, M. Takahashi, H. Yamanoto, T. Kakui, H. Matsumoto, A. Kurita and M. Kumada, J. Am. Chem. Soc., 1978, 100, 290; (b) K. Tamao, T. Kakui and M. Kumada, J. Am. Chem. Soc., 1978, 100, 2268; (c) J. Yoshida, K. Tamao and M. Kumada, J. Am. Chem. Soc., 1980, 102, 3269; (d) K. Tamao, J. Yoshida, H. Yamamoto, T. Kakui, H. Matsumoto, M. Takahashi, A. Kurita, M. Murata and M. Kumada, Organometallics, 1982, 1, 355; (e) P. Xu, F. Wang, G. Fan, X. Xu and P. Tang, Angew. Chem., Int. Ed., 2017, 56, 1101. 
10 M. Arimoto, H. Yamaguchi, E. Fujita, M. Ochiai and Y. Nagao, Tetrahedron Lett., 1987, 28, 6289.

11 (a) S. Guo, F. Cong, R. Guo, L. Wang and P. Tang, Nat. Chem., 2017, 9, 546; (b) X. Jiang, Z. Deng and P. Tang, Angew. Chem., Int. Ed., 2018, 57, 292; (c) F. Cong, Y. Wei and P. Tang, Chem. Commun., 2018, 54, 4473; (d) H. Yang, F. Wang, X. Jiang,
Y. Zhou, X. Xu and P. Tang, Angew. Chem., Int. Ed., 2018, DOI: 10.1002/anie.201807144.

12 For selected reviews, see: (a) S. Bräse and K. Banert, Organic Azides: Synthesis and Applications, Wiley-VCH, Weinheim, 2010; (b) S. Bräse, C. Gil, K. Knepper and V. Zimmermann, Angew. Chem., Int. Ed., 2005, 44, 5188. 